\title{
Local Context and Global Strategy: Extending the Integration Responsiveness Framework to Subsidiary Strategy
}

\author{
Klaus E. Meyer \\ China Europe International Business School \\ Shanghai, China \\ k.meyer@bath.ac.uk,kmeyer@ceibs.edu
}

\author{
Saul Estrin \\ London School of Economics \\ London, UK \\ sestrin@lse.ac.uk
}

This version: April 3, 2013

Forthcoming in: Global Strategy Journal

\begin{abstract}
Acknowledgements: We owe thanks for helpful comments to editor Steve Tallman, three anonymous reviewers, Mike Peng, Joachim Wolf and especially Christian Stadler, as well as participants of the EIBA conference in Bucharest. We also gratefully acknowledge excellent research assistance from Angela Lei. The dataset collection and initial research was coordinated and supported by Copenhagen Business School, and sponsored by the Danish Social Science Foundation under grant number 24-01-0152. Any remaining errors are our own.
\end{abstract}




\title{
Local Context and Global Strategy: Extending the Integration Responsiveness Framework to Subsidiary Strategy
}

\begin{abstract}
The integration-responsiveness (IR) framework is a leading analytical tool of global strategy but it is less valuable in explaining the heterogeneity of strategic choice for subsidiaries within an MNE. We propose an IRE framework of subsidiary strategy that complements the IR framework for the subsidiary level with a third dimension - selling to local versus export markets (E). Resource-based considerations suggest that subsidiary strategies must fit the resources both the parent MNE and the local context. We examine how our three dimensions of subsidiary strategy are locally contingent. We suggest that local resource endowments, local competition, and the distance between the home and host country influence the use of responsiveness and exporting strategies, but only to a small degree integration strategies. We find empirical support for hypotheses developed from these arguments using survey data from MNE subsidiaries in two Central and Eastern European economies.
\end{abstract}

\section{Keywords:}

Integration, responsiveness, exports, strategy contingencies, subsidiary strategy, local context, distance. 


\section{Introduction}

Subsidiaries of multinational enterprises (MNEs) are simultaneously an integral part of the MNE and actors in a specific local context (Anderson, Forsgren and Holm, 2002; Garcia-Pont, Canales \& Noboa, 2009, Meyer, Mudambi and Narula, 2011). They combine the resources of the MNE with local resources in the host economy to create products or services which they can supply to local markets or export, perhaps but not exclusively within the MNEs global supply chain. Each subsidiary contributes to the MNE's global strategy by assuming a specific role that creates and exploits opportunities in its specific local context (Ambos, Andersson and Birkinshaw 2010; Birkinshaw and Morrison, 1995; Cantwell and Mudambi, 2005).

At the levels of the MNE, strategies are commonly conceptualized with the integration-responsiveness (IR) framework (Prahalad and Doz, 1987; Bartlett and Ghoshal, 1989; Devinney, Midgley and Venaik, 2000), which (implicitly) assumes that MNE strategies are adopted uniformly and consistently across all subsidiaries. However, in practice subsidiaries vary considerably in what they do and how they partake in global strategies. This variation of subsidiary roles within an MNE depends on both the MNE's global strategy and resources and the availability and character of resources accessed locally (Anand and Delios, 2002; Hennart, 2009); in other words on the interaction of firm-specific and country-specific advantages (Rugman \& Verbeke, 2001). Thus, MNEs create linkages between their diverse subsidiaries that in turn exploit opportunities in different kinds of local contexts (Anderson, Forsgren and Holm, 2002; Meyer, Mudambi and Narula, 2011). Consequently, subsidiaries vary with respect to the markets into which they sell: domestic or international (De La Torre, 1971, Egelhoff, 1982, Estrin et al., 2008, Kogut 1995). Hence, we propose to extend the ideas of the IR framework to understand the determinants of subsidiary strategy by adding export orientation as a third dimension in our IRE framework.

In this study, we examine how the three dimensions vary with respect to how and how much they are shaped by the local environment of the subsidiary. Of the three dimensions of the IRE framework, the integration dimension is, as we will argue below, to a large extent determined by the MNEs global strategy: effective implementation of an integration strategy requires the participation of all subsidiaries. In contrast, local 
responsiveness will be sensitive to changing local conditions in the host economy, including the quality and availability of local resources of value in an export programme and the intensity of local market competition. Likewise, our added dimension, export orientation, depends on these local conditions. ${ }^{1}$ Thus, the $\mathrm{R}$ and $\mathrm{E}$ dimensions of subsidiary strategy are contingent on the specific locational advantages in any host economy (Dunning, 1998; Meyer, et al., 2009a) and the ability of the MNE to exploit such locational advantages (Zaheer and Nachum, 2011). In consequence, these two dimensions may be adjusted to the local context at each location, while integration is primarily driven by parent level factors and is largely independent of local considerations.

Subsidiary strategies along the IRE dimensions also depend upon the positioning of the MNE relative to the host context, and hence the cultural and resource distance between home and host country (Estrin, Baghdasaryan and Meyer, 2008; Kogut and Singh, 1988; Tihanyi, Griffith and Russell, 2005). Different constellations of local and parent resources can be exploited by different strategies. However, large differences can inhibit for example knowledge transfers and in consequence the effectiveness of complex organizational structures with multi-directional knowledge flows (Kostova and Roth, 2002). Hence, distance creates opportunities for subsidiaries to develop export oriented strategies, while potentially reducing the effectiveness of local responsiveness strategies.

We test these ideas on a proprietary dataset of 306 MNE subsidiaries in two East European economies, Hungary and Poland. As a special feature, we are able to measure local resources at levels below that of the nation, specifically at the level of industry (for local competitors) and province (for local human resources). The dataset is thus appropriate to test the effects of local resources and distance on subsidiary strategies because it displays heterogeneity of local contexts, and high variability in the distances to source countries. The results support the impact of distance, local competition and local resources for the responsiveness and export-orientation dimensions of subsidiary strategies while, as expected, parent level variables dominate the choice of an integration strategy.

\footnotetext{
${ }^{1}$ This extension was inspired by Ghemawat's (2007) suggestion to add 'arbitrage' strategies, but distinguishes arbitrage of parent resources (the traditional model) from arbitrage of resources obtained locally (export orientation).
} 
We thus offer several contributions to global strategy research. First, we demonstrate how subsidiary strategies can be characterized by an IRE framework that integrates export orientation of the subsidiary as a third dimension with the traditional dimensions of integration and responsiveness. Second, we develop a contingency approach that explains how the three strategic dimensions in each subsidiary are contingent on its local contexts. Third, we offer more fine-grained theorizing as well as empirical evidence on the impact of local context by exploring the resource aspects of local environments in the analysis of subsidiary strategies. Fourth, we contribute to the long-running debate in international strategy research on the role of distance (Shenkar, 2001; Zaheer, et al., 2012) by showing that opportunities arising from resource distance encourage export strategies, while the costs of resource distance inhibit local responsiveness.

\section{Subsidiary Strategy and the IRE Framework}

Like independent firms, subsidiaries pursue strategies to achieve economic objectives in their chosen market place, but they do so interdependently with their parent MNE (Garcia-Pont, Canales and Noboa, 2009, Taggart, 1997). The parent provides them with access to resources, but also insists on sharing their resources and places constraints on the strategic initiatives they may pursue (Birkinshaw and Morrison, 1995, Ciabuschi, Dellestrand and Martin, 2011).

In recent years, these subsidiary strategies have become more diverse with the advance of globalization and the associated geographic 'fine-slicing' of activities within value chains as well as the increasing sophistication of host economies in emerging markets (Doh, Bunyaratavej and Hahn, 2009; Kedia and Mukherjee, 2009). Subsidiaries are specializing more narrowly on well-defined activities, and they trade their products and services with subsidiaries at other locations as part of the MNE's global strategy (Buckley, 2009; Koza, Tallman and Ataay, 2011; Rugman, Verbeke and Yuan, 2011). At the same time, MNEs increasingly assign to their subsidiaries specific roles that combine local resources with the MNE's global competences and contribute particular activities to the global operations of the MNE. Moreover, these roles may evolve over time (Birkinshaw and Morrison, 1995; Santangelo and Meyer, 2011). For example, the successful development of local technology may lead subsidiaries, originally located to 
exploit low cost manufacture for the MNEs home market, to turn their attention to exporting to their own regional market.

The integration-responsiveness (IR) framework, originally conceived for the analysis of MNEs at the global level, provides our starting point for analysing these subsidiary strategies. While indicating some of the key strategic trade-offs for the parent, the framework is limited because it does not take into account the nature of the subsidiary’s position in the value chain (Devinney, et al., 2000, Rugman et al., 2011). In particular, it implicitly assumes that subsidiaries provide local markets with the products and services of the MNE (adapted to varying degrees to local markets). However, MNEs also create subsidiaries that supply global operations by tapping into local resources. Hence, the direction of intra-MNE trade and knowledge flows is not unilateral but bilateral as MNEs exploit comparative advantages of different local contexts and as these context change, for example as a result of rapid local economic development (Meyer, et al., 2011; Yang, Mudambi and Meyer, 2008). Thus, some subsidiaries attain strategic mandates to serve internal and external markets in multiple countries (Birkinshaw and Morrison, 1995; Birkinshaw and Hood, 1998). Such specialization within MNEs has become increasingly important as globalization enables supply chains to become more regionally differentiated, yet at the same time more operationally integrated (Buckley, 2009; Dunning and Lundan, 2008; Koza et al., 2011; Meyer, 2006; Rugman et al. 2011).

We address this limitation by building on the concepts of the IR framework to propose a new three dimensional IRE framework of subsidiary strategy. First, integration of MNE operations across subsidiaries creates two very different types of benefits. It allows exploitation of economies of scale and scope for the MNE as a whole, or perhaps regionally organized parts, by sharing centralized resources (e.g. product development) over a larger volume of sales. Hence, unit costs can be reduced as fixed costs are spread more widely. Moreover, integration allows MNEs to tap into multiple pools of local resources and communities of practice, and to integrate them into their internal resources and communities of practice (Ciabuschi et al., 2011; Gupta and Govindarajan, 2000; Tallman and Chacar, 2011). From a subsidiary perspective, this standardization and 
knowledge integration happens at 'above-subsidiary' level, though not necessarily at a global level (Ghemawat, 2007, Rugman et al., 2011). ${ }^{2}$

If integration is to succeed, the participation of a subsidiary in an integration strategy cannot be optional because if an independence-minded subsidiary is able to opt out, this could undermine the benefits of the entire MNE strategy. Even though local conditions may provide alternative strategic options to subsidiaries, these are unlikely to be permitted once the head office has determined upon a global (or regional) integration strategy. In such cases, the strategic decisions for the subsidiary are taken above the level of the host economy; the determinants of such a strategy will be driven by the prerogatives of the parent MNE.

Second, responsiveness draws on a philosophy of 'All Business is Local' (Quelch and Jocz, 2012) and aims for a high degree of local adaptation of products and processes by giving the subsidiary greater leeway to make its own sales decisions in the local context. However, such local customization is not costless; it involves changes to products and internal processes (Solberg, 2000; Dow, 2006; Grewal, Chandrashekaran and Dwyer, 2008), which reduce standardization and increase the complexity of the interface between parent and subsidiary. Responsiveness thus requires intensive interaction between the parent and the subsidiary as they jointly work out how core competences can be exploited while adapting processes and products to local conditions. Responsiveness strategies are therefore highly sensitive to the local business context. The discussion suggests that such strategies are facilitated where (i) the local environment creates idiosyncratic conditions that are very different from those of the MNEs country of origin, (ii) frictions in communication and knowledge flows between headquarters and subsidiary are low, and (iii) competitive pressures from local competitors are strong, raising the (opportunity) costs of failing to adapt to the local market.

Third, the newly added dimension, export orientation, captures the degree to which subsidiaries serve markets outside their host economy. This dimension reflects the essence of comparative advantage in international trade, namely the ability of businesses

\footnotetext{
${ }^{2}$ Integration does not necessarily take place at the headquarters level, contrary to what was implied by Bartlett and Ghoshal (1989). Recognizing the regional nature of business (Rugman and Verbeke, 2004), many MNEs integrate operations between the national and the global level, for example by using regional headquarters (Benito, Lunnan and Tomassen, 2011; Birkinshaw, et al., 2006).
} 
to benefit from the exchange of goods that are available at different qualities and prices at different location (Ricardo, 1817). MNEs are in a strong position to exploit such advantages because they have the organizational capabilities to recognize opportunities and to transform and combine resources before selling them in a different marketplace. From a subsidiary perspective, export-orientation strategies enable the exploitation of host county comparative advantages to sell on to customers in third countries, perhaps geographically close or perhaps seeking at a reasonable cost the particular bundle of goods that can be created by combining the MNE expertise with the local economic advantages. Subsidiaries can also participate in integrated but geographically dispersed MNE networks and value chains (De la Torre, 1971, Doh, et al., 2009; Kogut, 1985). ${ }^{3}$ Export-orientation strategies at the subsidiary level are therefore more likely in local contexts where distinct competences - for example specific types of human capital or low labor costs - can be exploited (Estrin et al., 2008). In particular they are more likely in locations with (i) low cost of doing business locally, (ii) low frictions to cross-border transactions, and (iii) distinctive local resources, e.g. human capital, that differs from those to which the MNE has access elsewhere.

The three subsidiary strategies are non-exclusive and can be combined in a variety of ways. Our graphical illustration in Figure 1 therefore takes the form of a cube. Theoretically, a given MNE subsidiary could be positioned at any point within this three dimensional space. However, the different strategies vary in their demands on the subsidiary, creating important strategic trade-offs. A (hypothetical) subsidiary choosing low integration, low responsiveness, and low export orientation would not be well positioned to take advantage of the possibilities of internationalization of operations. On the other hand, an MNE trying to achieve integration, responsiveness and exportorientation at the same time likely faces complex demands on its organizational and leadership capabilities. Hence, this is unlikely to be the optimal choice except for very specific cases (Ghemawat, 2007). This interdependence requires treating the decision about which strategy to adopt as a simultaneous choice. We return to this issue in the Methodology section.

\footnotetext{
${ }^{3}$ The analysis of the interaction between MNE strategy and local context may be different when the local resources under consideration are natural resources. Our discussion refers to manufacturing and service exports but the natural resource sector is beyond the scope of this paper.
} 
*** Figure 1 here ***

\section{Subsidiary Strategy and Local Context}

MNE subsidiaries develop their own bundles of resources by integrating parents’ resources with selected local resources (Rugman and Verbeke, 2001). The heterogeneity of resource bundles thereby created in each subsidiary drives the diversity of subsidiary strategies (Verbeke and Yuan, 2013). In other words, the nature of inputs that a subsidiary has at its disposal locally determines the outputs it can profitably supply, and the markets in which it can compete. We propose that subsidiaries' responsiveness and export orientation strategies are contingent on the level of local resource quality; these are what attract foreign investors to locate different types of operations at different locations (Dunning and Lundan, 2008).

Moreover, the opportunities that a subsidiary pursues along the responsiveness and export-orientation dimensions of subsidiary strategy also depend on the relative position of the foreign parent to the host context; its distance (Shenkar, 2001; Tihanyi et al. 2005; Zaheer et al., 2012). In contrast, integration strategies are implemented coherently across the whole MNE and hence are less contingent on local contexts. These arguments provide the structure for our hypothesis development, previewed in Table 1.

\section{*** Table 1 about here ***}

\section{Resource Endowments of the Host Economy}

The resources of the host economy are an essential building bloc of any subsidiary as MNEs combine their firm-specific resources with locational advantages in the host environment (Dunning and Lundan, 2008, Zaheer and Nachum 2011). Foreign investors may acquire them in a bundled form by taking over a local firm, or by forming a joint venture with a local partner (Anand and Delios, 2002, Hennart, 2012; Li, Li \& Shapiro, 2012; Meyer, et al., 2009b). Even for a greenfield operation, an entrant would acquire (or rent) local real estate, hire local staff, and source from local suppliers (e.g. utilities) but in this case primarily from the open markets of the host economy. The quality and costs of local resources thus are major constraints on the strategic choices available to subsidiaries in any local context (Dunning, 1998; Hennart, 2009; Meyer, et al. 2009a).

The resources of host economies evolve over time, especially in rapidly growing emerging markets, creating shifting patterns of national comparative advantage (Dunning 
and Narula, 2000; Manning, Massini and Lewin 2008; Xu and Meyer, 2013). Some countries offer specialized resources that create opportunities for exporting products and services that require significant local supplies of this particular type of resource (Doh et al., 2009). In emerging economies, the most likely specialization attracting MNEs for export opportunities ${ }^{4}$ arise from their comparative advantage in unskilled and semiskilled labor at relatively lost cost (Kogut, 1985; Dunning, 1998, Meyer and Peng, 2005). The key phenomenon is not the quality of the human capital of the labor force but its ready supply and low cost. This availability opens the potential for MNEs to relocate the labor-intensive stages of disaggregated value chains in order to take advantage of lower labor costs. Firms may therefore manufacture their own components in emerging markets as exports to supply to their own factories further along the value chain, as for example with components manufactured in Central and Eastern Europe (CEE) for car manufacturers in Germany. Other industries use such manufacturing hubs for regional supply of final products, as for example garments made in CEE under Italian brands.

On the other hand, locally responsive strategies require the integration of the MNEs technologies with local knowledge (Solberg, 2000; Dawar and Chattopadhay 2002; Dow 2006). Adapting a product or process of the MNE to local conditions entails a local product development process that requires that the local workforces have strong skills and qualifications. For example, KFC famously outperformed McDonalds in China through a higher degree of local adaptation. This adaptation was achieved through a strong focus on developing human resources, and putting these to work to generate product and process innovations that fit the particular context in which KFC has been operating (Liu, 2007). Indeed, if the qualifications of the local workforce are weak or insufficient, this could be a major obstacle to effective responsiveness and thus reduce the subsidiary’s ability to generate localized products and processes. Hence, we suggest:

Hypothesis 1a: The stronger are local (human) resources in an emerging economy, the less likely are MNE subsidiaries to adopt export oriented strategies.

\section{Hypothesis 1b: The stronger are local (human) resources in an emerging economy,} the more likely are MNE subsidiaries to adopt responsiveness strategies.

\footnotetext{
${ }^{4}$ Other than in the supply of natural resources. There are no natural resource industry firms in our sample.
} 


\section{Local Competition}

Foreign subsidiaries face local firms as potential competitors that serve the same markets, especially but not only domestically, and compete for the same customers. The local firms' strength is likely to be grounded in indigenous resources, including intangible ones such as networks and team-embedded knowledge. Foreign investors may be able to tap into these resources, for example by local sourcing or by forming joint ventures with local partners. Hence, a local network of strong local business partners, especially suppliers, could in principle assist subsidiary strategies to export if the two choose to cooperate because foreign investors are better positioned than local competitors to exploit national comparative advantages internationally. At the same time, strong local competition creates pressures on MNE subsidiaries to seek markets outside the host economy, where they would enjoy competive advantage vis-a-vis local competitors in the host country. In contrast, if local firms are weak, subsidiaries will be less able to exploit local comparative advantages internationally and hence less likely to adopt export based strategies.

Strength of local competitors can also push MNE subsidiaries in the direction of local responsiveness. The stronger local firms' resources are, the more they are capable of attracting knowledge spillovers (Blalock and Simon, 2009; Meyer and Sinani, 2009), of launching competitive counterattacks (Chen, 1996, Smith et al. 2001), and of developing the skills to become real competitors in international markets (Peng, 2011). Local competitors, with their local knowledge and access to local resources, also tend to have certain competitive advantages in serving the demand for localized products. Their competitive threat would therefore lead MNEs competing in local markets to attempt more finely to adapt their products to local customers' demand, and to react in a timely manner to their competitors' actions. A timely response, however, requires that decision makers have a sharp awareness of the competitive dynamics (Yu and Cannella, 2007), and this is more likely when subsidiaries can respond locally. Hence, the stronger local competitors, the more a foreign investor has to address their competitive threat through responsiveness in local markets. Hence, we propose:

\section{Hypothesis 2a: When the resources of local competitors are stronger, an MNE} subsidiary is more likely to adopt export strategies. 


\section{Hypothesis 2b: When the resources of local competitors are stronger, an MNE}

subsidiary is more likely to adopt responsiveness strategies.

\section{Distance of Culture, and of Resources}

The positioning of the MNE relative to the host economy is also a major determinant of subsidiary strategy. Specifically, the distance between the home country of an MNE and the host countries into which it has invested has been identified as a major influence on international business. Distance is a multidimensional construct (Shenkar, 2001; Ghemawat 2007; Zaheer et al., 2012) and we concentrate on cultural (Kogut and Singh, 1988, Tihanyi et al., 2005) and resource distance (Estrin et al., 2009). Distance has two principal effects: it raises the costs of doing business, especially for communication intensive strategies, and it creates opportunities for arbitraging or combining resources. Hence, both business opportunities and the costs of doing business are likely to increase with distance (Slangen and Hennart, 2008, Zaheer and Hernandez, 2011).

Cultural distance is an important source for export opportunities because the greater the distance between two locations, the more likely that a particular location has substantive comparative advantages in certain products or resources relative to other locations. Cultural distance increases the scope for arbitraging culturally embedded products (such as country-of-origin brand images), or products that in their production are influenced by culture (such as design or entertainment). Moreover, the more different are any two national contexts, the greater the possibilities of finding synergistic resource combinations that allow the creation of new products and services. In other words, diversity of cultures is a source of innovation that enables export strategies.

However, cultural distance increases the costs of communication and coordination, and can therefore inhibit mutual understanding and the levels of trust between individuals from organizations in the two countries. This in turn affects for example the transfer of knowledge and practices (Yang et al., 2008) and the effectiveness of multi-site teams when they depend on personal relationships and trust between individuals (Jensen and Szulanski, 2004, Kostova and Roth, 2002). Hence, it becomes more difficult to implement communication intensive organizational forms such as matrix organizations and delegated decision making power. To bypass such obstacles, MNEs 
investing in distant locations have been shown to avoid communication-intensive modes of entry such as acquisitions (Barkema and Vermeulen, 1998; Harzing, 2002; Larimo, 2003) or joint-ventures (Kogut and Singh, 1988).

Moreover, if local managers were to take charge of an operation that is culturally distant from headquarters, their leadership would likely emphasize their own values and the local culture. They may in particular aim to reduce frictions within the local operation and accommodate normative and cognitive pressures to fit with the local environment. However, for an MNE this outcome is not optimal because it reduces the cultural fit between headquarters and subsidiaries. A subsidiary singularly focused on local fit may become an obstacle to MNEs' managerial control over the subsidiary in precisely those contexts that are less well understood and where communications are harder and more expensive. MNEs thus are likely to use higher levels of integration with for example more expatriate managers that facilitate knowledge flows between headquarters and subsidiaries, and help to reduce potential tensions between units (Colakoglu and Caligiuri, 2008).

Local stakeholders may call for locally adapted products, especially for culturally sensitive products such as foods and entertainment (Dawar and Chattodaphay, 2002), even though this may not be in the interest of the MNE. The costs of generating effectively adapted products are substantially increased by the higher level of frictions in communications as effective responsiveness requires intensive interaction. Hence, we suggest that in distant countries, products and processes will be less adapted to the local context.

Hypothesis 3a: The greater is the cultural distance, the more likely are MNE subsidiaries to adopt export oriented strategies.

\section{Hypothesis 3b: The greater is the cultural distance, the less likely are MNE subsidiaries to adopt responsiveness strategies.}

Distance can also exist with respect to human resources. Heterogeneity of human resources creates many business opportunities for MNEs and their subsidiaries, but also costs; at the level of subsidiaries, these are associated with 'human resource distance' between headquarters and subsidiary (Estrin, et al., 2009). Variation in the types of 
qualifications and skills of the workforce across different host locations provide opportunities for the MNE to produce different products or stages of the value chain in different places, and hence to "arbitrage" these differences through export oriented operations in foreign locations (Doh et al., 2009; Kedia and Mukherjee, 2009). As these differences evolve, for example with changing education and skill levels in previously low cost environments, subsidiaries may be able to exploit their combination of the MNE brand and their own locational advantages, to pursue new export opportunities at a regional level. In fact, distance in resource endowments is the essence of the comparative advantages that MNEs and their subsidiaries can exploit in designing their exporting strategies (Kogut, 1985).

The essence of a responsiveness strategy is the parent and the subsidiary working closely together to exploit the organization's core competencies in ways that fit the local environment (Ghemawat, 2007). This is made harder if the human resources differ widely because the costs of communication and decision-making are higher, even though distinct contributions of the local workforce may create new values. These differences in human resources can be an obstacle to local responsiveness because they reduce the ability of the local workforce to match the global product with the local conditions in order to develop locally adapted products or processes that still utilize the resources of the parent. As discussed above, effective responsiveness requires intensive communication, and that is more difficult when local human resource profiles are very different from what is found in the MNE. Hence, we propose:

Hypothesis 4a: The greater is the human resource distance, the more likely are MNE subsidiaries to adopt export oriented strategies.

Hypothesis 4b: The greater is the human resource distance, the less likely are MNE subsidiaries to adopt responsiveness strategies.

\section{Dual Embeddedness: Local v MNE}

The integration dimension is core to the original IR framework applied at the MNE level, but as we have argued above is only to a limited degree (if at all) varying across subsidiaries. The balance between the dual institutional pressures of the local context and the parent MNE (Kostova and Roth, 2002; Kostova, Roth and Dacin, 2008) is likely to 
shift in favour of the latter when the parent has worldwide operations that rely on close coordination across all business units, as is necessary to implement an integration strategy. The success of an integration strategy depends on every contributing subsidiary participating in centralized services and knowledge integration within the MNE. In such an MNE, a subsidiary optimizing its own performance locally by alignment with the local context could undermine the performance of the MNE as a whole; for example by damaging the global brand.

At the same time, integration strategies seek to exploit multiple pools of local knowledge and communities of practice, and to embed such knowledge in their internal communities of practice (Anderson et al., 2002; Tallman and Chacar, 2011). The recent trends of knowledge sourcing and innovation in emerging economies illustrate the potential importance of such local competencies for innovation at a global level (Govindarajan and Ramamurti, 2011). Hence, we suggest that the choice of an integration strategy will not be substantially influenced by the aspects of local context discussed so far.

Integration strategies are particularly relevant to knowledge intensive MNEs where competitive advantages are generated through the effective sharing of innovations and ideas (Gupta and Govindarajan, 2000; Kobrin, 1991; Mudambi, 2008). With heavy investments in product development, technology intensive businesses depend on their ability to recoup that investment by speedily rolling out new products globally, which requires coordination at above-subsidiary level. Hence, we expect MNE characteristics to dominate in the decision to pursue an integration strategy, largely to the exclusion of factors arising in the local context. From the perspective of the subsidiary, this implies:

\section{Hypothesis 5: Local context variables do not substantively determine MNE subsidiaries' choice of integration strategies.}

Hypothesis 5 cannot be tested in the same way as the other four hypotheses because at the subsidiary level it proposes the absence of an effect. Empirically, a nonsignificant relationship could be due to noise in the data rather than providing evidence for the theoretical arguments. Even so, we diverge from the custom of not stating hypotheses which are not directly testable because the reasoning behind hypothesis 5 
constitutes an important aspect of our theoretical argument; indeed our model would be incomplete without it. We would infer (weak) support for hypothesis 5 from an equation to determine the subsidiaries' choice of integration hypothesis if the effects of the local variables discussed in hypotheses 1 to 4 prove not to be significant while MNE-level variables are more important than in the export or responsiveness equations.

\section{Summary}

The characteristics of the host economy in terms of resource endowments and distance to the country-of-origin have been argued to impact on the choice of subsidiary strategy along the three dimensions of our IRE framework. Local context variables influence strategies at the subsidiary level, while the choice of integration strategy is determined primarily by parent influences (Table 1 ).

These three dimensions of subsidiary strategy are interdependent. The trade-off between integration and responsiveness is well established in the literature; indeed some scholars think of integration-responsiveness as a single scale (Doz, et al., 1981; Roth and Morrison, 1990). Thus, we expect a negative association between integration and local responsiveness. Likewise, a trade-off exists between export orientation and local responsiveness because export oriented ventures need first and foremost to reflect their markets, which are outside the host country.

\section{Methodology}

\section{Data}

Our propositions concern the effects of the local environment and of home-host country distances on MNEs subsidiary strategy. To explore this empirically we require a dataset that has a wide variation in these two dimensions. We use a dataset based on a questionnaire survey conducted in 2003 in two countries of Central and Eastern Europe, Hungary and Poland that has been used in earlier studies (Estrin et al., 2008; Estrin et al., 2009; Santangelo and Meyer, 2011; Yang et al., 2008). Both countries have undergone economic transition in the early 1990s - prior to the data-collection - and began to attract large amounts of FDI from a wide range of source countries. They offer investors a range of attractive resources, including human capital and institutional systems well under way to supporting a market economy. Both conditions, however, vary considerably across provinces and industries, allowing us to test for the impact of such variations. 
The data were collected using a questionnaire that was administered to the chief executive of MNE subsidiaries. The sample was constructed such as to include all subsidiaries with foreign equity stakes of at least ten per cent, established in the country within ten years before the survey, and employing at least ten people. The local research teams participated in the development of the questionnaire instrument through pre-survey research meetings, questionnaire pilots and case studies. They contacted the firms initially by mail, and followed up where appropriate through telephone calls and personal meetings. In total, 424 responses were received (200 in Poland, 224 in Hungary); a response rate of 13 per cent. ${ }^{5}$ After missing values, the number of observations was 306.

\section{Dependent Variables}

The three dependent variables at the heart of our hypotheses are integration, responsiveness and export orientation strategies. They are operationalized as follows. Integration is based on two Likert scale items from the questionnaire 'The foreign parent has centralized many functions such as R\&D, finance and procurement.' and 'the foreign parent has to a high extent standardized products and services worldwide'. We averaged the score over these two items to measure Integration. Responsiveness is based on two Likert scale items 'Your firm conducts many major functions locally' and 'your firm has adopted its products and services to a high degree to the local context' that have been averaged in the same ways as for Integration. Export orientation is based on the percentage of sales exported, as reported in the questionnaire. The dependent variables have been standardized. As expected, the correlations between these three dependent variables are low but non-negligible (between 0.12 and 0.30 ), indicating that the three dimensions of the IRE framework are non-exclusive and are being combined differently by different firms.

\section{Explanatory variables}

Our first two explanatory variables have been derived from questionnaire responses of firms operating in the same local industry. As these variables are measures of the local environment, and every individual's response may be subject to personal biases, we constructed the variables in a novel way that also reduces the possibility of common

\footnotetext{
${ }^{5}$ As some of the firms were not operating (especially in Poland) or not foreign-owned (in Hungary), and should theoretically not have been in the sample frame, this rate provides a low estimate.
} 
method variance in the data. Specifically, we pooled responses in the same specific local community to create a value for that community. The quality of local human resources is based on a 3-item Likert scale measure of the extent to which qualified individuals were available locally at acceptable costs, the items being professionals, operational management, and skilled non-managerial labor (Cronbach's alpha 0.82). This index is the average scores for all firms operating in the same local province in respectively Hungary and Poland. The resources of local competitors are based on a 5-item Likert scale measure by different measures of firm performance: quality and range of products, quality and range of services, management capabilities, marketing capabilities, and level of technology (Cronbach's alpha 0.91). ${ }^{6}$ This index is averaged across all firms operating in the same local industry at 3-digit SIC level (or higher level where appropriate) in respectively Hungary and Poland.

The concept of distance is central to recent international business research (Kostova, 1999; Tihanyi et al., 2005), yet its measurement remains controversial. Many studies employ indices based on Hofstede’s (1980) work on national culture. However, there are widespread concerns regarding the validity of these indices. For example Hofstede (1980) did not employ techniques of statistical validation that would nowadays be expected (Shenkar, 2001; Javidan, et al., 2006). In addition, the underlying data were collected in the 1970s, while some values, including those for the two host countries in our study, are later estimates based on different populations. Hofstede argues that the indices are still valid because culture is essentially constant over time (Hofstede, 2010), but this view is highly controversial. If culture evolves, then it is necessary to replace Hofstede’s indices with more recent data.

We thus follow Estrin et al. (2009) and employ indices constructed in the same way as the Kogut-Singh index, but using data from the more recent GLOBE study (House, et al., 2004) to capture the distance between the MNEs home country and respectively Hungary and Poland as host countries. This study recently developed nine indices based on new data and contemporary empirical techniques (Javidan et al., 2006). We select their 'practices' indices rather than the 'values' indices because foreign

\footnotetext{
${ }^{6}$ The questions regarding local human resources and local competitors asked for assessment at two points in time: "when the foreign investment was established" and "now". For the current research, only the second entry "now" was used.
} 
investors are concerned primarily with the practices they actually encounter in a host country, rather than desirable states of the world as reflected in the 'values' indices (Estrin et al., 2009). The variable cultural distance has then been constructed employing the Kogut-Singh (1988) formula to GLOBE practices indices.

To measure human resource distance, we likewise follow Estrin et al. (2009). They used four items measuring the level of human resources at a national level, two relating to educational achievements (average years of schooling, tertiary education over population ratio) and two items relating to spread of information technology (number of computers, internet hosts over population ratio). The human resource distance variable was then constructed using the Kogut-Singh (1988) formula.

Research intensity of the parent MNE has been proxied by the parent's R\&D expenditures. This has been obtained by a Likert scale introduced in the questionnaire, which ranges from 1 (research expenditures of 0 to $0.5 \%$ of global sales) to 7 (over 20\% of global sales). However, this variable was subject to a substantial number of missing values. To avoid creating selection bias by dropping these observations, we set the missing values to zero, and created an additional selection dummy called R\&D control, a procedure used for example by Singh (2008). ${ }^{7}$

\section{Control variables}

We have entered a number of additional control variables into the equation and these were primarily chosen to address heterogeneity between MNEs. Thus, we control for the age of the subsidiary with the variable Year, which is the date of the legal establishment. We include two dummies to control for the degree of diversification of the parent firm called Diversification-related and Diversification-unrelated. The base case here is a focused strategy of the parent. The Relative size of the parent and the focal subsidiary in terms of sales is captured with a six point scale capturing the turnover of the subsidiary relative to the parents ranging from 1 (less than $0.1 \%$ ) to 6 (over 20\%). Furthermore, we control for industry-specific effects with eight industry dummies. Finally, CEE operations is a dummy variable taking the value of 1 if at the time of subsidiary establishment the MNE had other operations in Central and Eastern Europe.

\footnotetext{
${ }^{7}$ We would like to thank an anonymous referee for suggesting this course of action.
} 
Table 2 reports the descriptive statistics and the correlations between the variables. All the correlations between explanatory variables are below 0.20 , thus providing no indication that multicollinearity might be present in the data.

*** Table 2 about here ***

As several variables have been generated through a questionnaire, it might be suggested that common method variance may be present in the data. To minimize the risk of common method bias affecting our results, we have undertaken the following actions recommended by the pertinent literature (Chang, van Witteloostuijn and Eden, 2010): First, in our empirical analysis, two of the focal explanatory variables (namely the distance measures) have been taken from archival sources, thus eliminating the common method variance for these variables. Second, two further explanatory variables, local human resources and local competitors, have been measured by multi-respondent data, thus capturing local context at respectively the local region and local industry level. Third, in designing the questionnaire, we have used different types of measurement (e.g. percentages for $R \& D$, Likert scales for responsiveness and integration), and distributed the items used in this paper in different parts of the questionnaire. Together, these measures essentially eliminate the possibility of respondents using cognitive models associated with our theoretical model when completing the questionnaire.

\section{Empirical model}

Our theoretical framework suggests that MNE subsidiaries develop a strategy that may consist of different combinations of integration, responsiveness and export orientation, and that the selection between these three elements may not be independent. However, our theory has not suggested any variables that would allow us to identify separately the determinants of each strategy, and thus we are unable to implement the estimation of a simultaneous equation model. Instead, we use indirect least squares (Greene, 2002), estimating for each a reduced form equation and taking into account the simultaneous nature of the decisions by including each of the remaining two dimensions as determinants of the third. Hence, each separate regression equations contain link variables - i.e. the 'other two' dependent variables - to capture the interdependence of the models. In other words, we have three relationships where the 'other' dimensions in 
each appear as an explanatory variable - which in two of three cases we expect to be significant. The three equations are therefore:

$$
\begin{aligned}
& I=f(\text { local context }, \text { parent context }, R, E, \text { controls }) \\
& R=\text { f(local context, parent context }, I, E, \text { controls }) \\
& E=f(\text { local context }, \text { parent context }, R, I, \text { controls) }
\end{aligned}
$$

where I, R, and E represent subsidiary strategies of responsiveness, integration and export orientation respectively, and local context, parent context and controls are vectors of independent variables discussed above. Each equation is estimated separately using ordinary least squares.

\section{Results}

Table 3 reports the results of our three regressions. The overall model F-statistics are significant at the $99.9 \%$ level, and the fit indicated by the adjusted $\mathrm{R}^{2}$ is higher for the responsiveness and export equations ( 0.23 and 0.32 ), but lower for the integration equation (0.10) indicating as we might expect that our framework provides a weaker explanation for the subsidiary choice of integration strategy.

Commencing with Hypotheses 1a and 1b, we strongly confirm our prediction concerning the negative impact of local human resources on subsidiaries' adoption of export strategies. However, while the sign of human resource endowment on responsiveness strategies is positive as predicted, it is not statistically significant. We therefore we find support for Hypothesis 1a but not for Hypothesis $1 \mathrm{~b}$.

Hypothesis 2a and $2 \mathrm{~b}$ propose that the strength of local competitors has a positive impact on the likelihood of subsidiaries adopting responsiveness and export strategies. In fact, we find the coefficient on local competitors to be positive in the responsiveness and export strategy equations and significant at $0.5 \%$ and $1 \%$ level respectively. Hence, we can confirm both hypotheses. Thus, MNEs are more likely to pursue responsiveness strategies where local competitors are strong, which as we have argued above is likely due to the need to respond locally to competitive threats posed by those local competitors. At the same time, strong local competitors represent competitive advantages of the local contexts that MNEs may be able to exploit through export strategies.

Hypothesis 3a and 3b focus on the impact of cultural distance on the choice of subsidiary strategy. We find that cultural distance is not significant in any of the 
regressions. ${ }^{8}$ Hence, MNEs appear not to use cultural differences as a basis to develop and exploit comparative advantages. Perhaps this is because the opposing effects of increased cost and increased benefits of pursuing business across large cultural distances act to cancel each other out.

In contrast, we find strong support for Hypotheses 4a and 4b. As predicted, distance in human resources reduces the likelihood of subsidiaries adopting responsiveness strategies (at 5\% level); this is likely due to challenges of adapting products and/or processes when it is harder for human resources to work together. Moreover, human resource distance significantly (at $0.5 \%$ level) increases the probability that a subsidiary will adopt export strategies, thus enabling it to exploit comparative advantages arising from resource diversity.

The integration equation allows us to consider but not formally test Hypothesis 5. As expected, we find that none of the local context variables are significant for the choice of an integration strategy, but the research intensity of the parent firm is highly significant. Moreover, consistent with our argument, research intensity is not significant in any of the other equations. We interpret these results as being broadly consistent with Hypothesis 5: parent firm considerations and research intensity in particular, are more relevant for integration strategies than for either of the other two dimensions of subsidiary strategy. We cannot go further with a subsidiary based dataset.

The estimated coefficients for the control variables are in line with expectations. Subsidiaries of MNEs with operations elsewhere in Central and Eastern Europe are less export oriented; this probably reflects the fact that such a subsidiary is less likely to have a regional mandate as different countries of the region are served by different subsidiaries. Some of the industry dummies are highly significant in all three equations, supporting the importance of industry specific effects in the development of subsidiary strategies. Moreover, we find that subsidiaries that are large relative to the parent firm (in terms of sales) are significantly more likely to pursue export strategies, probably because economies of scale at the subsidiary level are important for realizing cost advantages in export strategies. There are no subsidiary age effects in our sample.

\footnotetext{
${ }^{8}$ We did a number of additional tests, including variations of control variables and an alternative measure of cultural distance based of Hofstede-indices instead of GLOBE-indices. The lack of significance of the various measures of the cultural distance variable was robust to these changes in specification.
} 


\section{Discussion}

An IRE Framework of Subsidiary Strategy

This paper advances an IRE framework of subsidiary strategy, which is developed by extending to the subsidiary level the IR framework of global strategy (Bartlett and Ghoshal, 1989). In so doing we add an export orientation dimension (Figure 1), and explore how the choice of subsidiary strategy is conditional on the local context. The IRE framework provides a basis to capture the diversity of subsidiary strategies within an MNE and it is hoped will stimulate future research.

With respect to the integration dimension, theoretical considerations suggest that it would not - or only to a limited degree - be contingent on the local context. Integration strategies are only likely to be effective if all (or all relevant) subsidiaries are engaged in central processes of coordination and knowledge sharing. Subsidiaries that opt out of these processes would potentially undermine not only their own performance, but also that of their parent MNE. We found parent level effects to be significant while local context variables were not in the integration equation, which is consistent with this idea. Thus we found that R\&D intensive MNEs are more likely to impose high levels of integration over their subsidiaries. However, these results are at best indicative and more research is required to identify more precisely the factors driving integration strategies. We also identified a negative trade-off between integration and local responsiveness strategies, thus confirming that apart from the outliers investigated by Bartlett and Ghoshal (1989), firms are rarely able to pursue integration and responsiveness strategies simultaneously.

Focusing on the $\mathrm{R}$ and $\mathrm{E}$ dimensions that we predicted to vary across local contexts, we find that the selection of local responsiveness strategies at the subsidiary level is negatively associated with human resource distance, and positively with the competitive threat from local competitors. Hence, distance reduces MNEs’ propensity to adapt locally. This might be surprising from a local point of view as foreigners from distant origins may be expected to need more responsiveness to match local customer needs. However, seen from the MNEs’ perspective, distance implies higher costs of responsiveness because of the increased complexity of the process of jointly developing 
new products when communication is inhibited by large differences in cultures or human resources. Therefore, MNEs are likely to avoid costly responses to local idiosyncrasies by focusing on niche segments where less responsiveness is required, e.g. standardized intermediate goods or brands for middle class customers. Interestingly, the choice of local responsiveness strategy was found not to be sensitive to the level of local resources, only to the difference between this and the quality of resources in the home economy. Hence, we find that adapting to local market needs does not require strong local resources, as long as the gap between human resources in the host and home economy is not too wide. This suggests that there can be some substitution of human resources between the home and host economy to implement responsiveness strategies in the host economy. For the choice of export orientation strategies, we find strong evidence that they associated with low levels of local human resources, but high levels of competitive strength of local competitors. At the same time, they are associated with high distance between headquarters and the host countries, especially human resource distance, and with subsidiaries that are the sole representative of their MNE in the region (as suggested by the CEE operations control variable). Hence, we find that export strategies are based on national comparative advantages based on the quality of local resource endowments as well as the relative position of the home and host countries; they are not significantly related to integration strategies.

Overall, these results suggest that the IRE framework of subsidiary strategy provides a powerful analytical tool to analyse global strategy and its implementation at the subsidiary level. In particular, the design of a subsidiary strategy involves a simultaneous choice along three dimensions: integration, responsiveness and exportorientation, though one of these dimensions, integration, is largely independent from the local context. This approach provides an extension of Bartlett and Ghoshal's theoretical framework originally developed to analyse global strategy by demonstrating how it should be modified as a framework for subsidiary strategies.

\section{Further Implications for MNE Strategy Research}

Our study provides important insights for a number of related lines of research on global strategy. First, for subsidiary strategy we outline how the key concepts of global strategy can be applied to the subsidiary level though this also requires certain adjustments. First, 
we need to take into consideration that not all subsidiaries are local market oriented, and hence we need to a) include export orientation as an additional dimension of subsidiary strategy and b) export orientation needs to be controlled for in the equations of integration and responsiveness. The subsidiary level IR framework in its cubic representation (Figure 1) provides a starting point for such theorizing; future research should both refine the model and further explore what combinations of the three dimensions of subsidiary strategies are used by which firms in which contexts.

Second, our theoretical framework may stimulate further research on the geography of MNEs and the interplay between MNEs and local context (Meyer et al., 2011; Mudambi, 2008; Rugman et al., 2011; Tallman and Chacar, 2011). In particular, our framework provides a differentiation of subsidiary strategies that should be useful for research on, for example, location choice and intra-MNE governance. Moreover, we show how strategies vary at the subsidiary level as a consequence of variations in local context, which suggests that different types of FDI are undertaken at different locations. Future research into the determinants of FDI hence ought to deconstruct the concept of FDI to differentiate the underlying strategies.

Third, our study contributes to explaining the interplay of what Rugman (1982) called firm-specific assets (FSAs) and country-specific assets (CSAs). The focal explanatory variables in our study are expressions of CSAs that foreign investors try to tap into, whereas FSAs enter our equations as control variables. We find that responsiveness and export strategies are largely driven by CSAs, while integration strategies are driven by FSAs. However, the CSA-FSA framework also suggests that FSAs and CSAs would interact, and that subsidiaries themselves develop subsidiaryspecific assets from the FSAs and CSAs that can tap into. Our data do not permit exploring these interactions empirically, but future research may be able to do so.

Fourth, for research on distance in international business, our focus on different types of strategy may provide explanations of the ambiguous effects found in earlier empirical research (Tihanyi et al., 2005, Zaheer et al., 2012). In particular, scholars have been puzzled why results on the distance-entry mode relationships have been inconsistent across studies (Shenkar 2001, Tihanyi et al., 2005). In part, this is because distance raises both the opportunities and the costs of doing business (Estrin et al. 2009, Slangen and 
Hennart, 2008, Zaheer and Hernandez 2011). Our results provide more specific insights, suggesting that for export strategies, the opportunities arising from synergies of diverse locations outweigh their costs. On the other hand, for strategies that require local responsiveness of products or processes, distance has a larger impact on costs than on opportunities.

Finally, our framework invites further theoretical work, for example by decomposing the concept of export orientation into more finely grained strategies. Rather than considering all exports together, there could be analytical insights to be gained from distinguishing between different types of exports. For example, one might consider the contrast between intra-MNE exports that serve as inputs to other stages of the value chain of the same MNE - i.e. internal but global value chains - and external exports that serve local markets in third countries. One might argue that intra-MNE exports are in fact associated with higher levels of MNE integration because the downstream unit needs closely to coordinate product specifications with the focal subsidiary. In contrast, exports to independent importers in third countries may in some MNEs fall into the responsibility of the subsidiaries, which are able to exploit local advantages in regional or even global markets. In our dataset, external exports account presumably for the largest part of exports, notably in form of regional mandates where thee affiliate in Poland or Hungary serves multiple Central and East European countries. Yet, it would be interesting for future research to explore conceptually and empirically the differences between intraMNE and extra-MNE exports.

\section{Future Empirical Research}

As with any empirical study, our data have limitations that may stimulate future research. First, we suggest developing further the measurement on the integration-responsivenessexport-orientation concepts. We have used questionnaire-based items for each element, two of which included a subjective assessment, while those for export are based on an objective measure (export share). Future research may further advance the proxies to capture the distinct features of each of the three types of strategies. More concise measurements incorporating objective data at the subsidiary level would help empirical work on subsidiary strategy, though we acknowledge that such information is usually 
treated as confidential by MNEs. Moreover, with a large dataset, future research may test for non-linear relationships and control for non-normal distributions (Estrin et al, 2008).

Second, future research may explore further local contingencies. Some of the variation in location is clearly at the level of geographic or political entities such as the nation state, while other variation emerges across sub-national entities and industries. Thus, we have measured local context variables by aggregating the perception of subsidiary managers operating in the same local industry or province, to capture the specific features of the local environment. However, future research may use multi-level analysis and combine levels of analysis, using datasets with a larger number of host countries, to be able to explore the role of country-level resources with indices based on archival data.

Third, future research may explore other local contexts, or a wider range of local contexts. We have chosen Poland and Hungary because they present the opportunity to investigate a population of relatively recently established subsidiaries from a wide variety of home countries, and the ability to address local resources at a sub-national level. However, results may be affected by the specifics of this region, such as economic transition and EU accession, which suggests replicating the study in other regions, or analysing subsidiaries across a large number of countries to explore country-level resources and competition, perhaps for MNEs from a single country of origin.

\section{Conclusion and Implications for Practice}

Our IRE framework provides a tool for explaining and distinguishing the strategies of MNEs at the level of subsidiaries. We find that MNEs implement different strategies for different subsidiaries, reflecting their fit with the pertinent local context. This approach provides a foundation for a richer treatment of subsidiary strategies in the strategic management literature. In particular, MNEs’ global strategies consist of multiple interrelated subsidiary (or business unit) level strategies that can be classified in terms of integration, responsiveness and export orientation. Subsidiaries have to simultaneously fit into their parents' global strategies and in the local context, and they can do so using the flexibility provided to them by the export and responsiveness dimensions of the framework. Future strategy research thus ought to investigate the strategies of MNEs contingent on the local contexts in which each of their subsidiaries operates. 
Our main message to managerial practice concerns the importance of integrated yet locally sensitive approaches to global strategizing and contingency thinking with respect to strategic fit in each specific local context. Different subsidiaries have different strategic roles within the global corporation, and hence different subsidiary level strategies. The IRE framework provides a useful way to think about at the subsidiarylevel. The corporate strategy of an MNE may set key parameters for all three dimensions, yet subsidiaries retain substantial strategic autonomy with respect to the responsiveness and export strategies to fit with their specific local context, notably the strength of local competition, the quality of human resources and the distance of human resources quality in the home and host economy. 


\section{References}

Ambos TC, Andersson U, Birkinshaw J. 2010. What are the consequences of initiativetaking in multinational subsidiaries, Journal of International Business Studies 41(7): 1099-1118.

Anand J, Delios A. 2002. Absolute and relative resources as determinants of international acquisitions. Strategic Management Journal 23: 119-134.

Andersson U, Forsgren M, Holm U. 2002. The strategic impact of external networks: Subsidiary performance and competence development in the multinational corporation, Strategic Management Journal 23(9): 979-996.

Barkema HG, Vermeulen F. 1998. International expansion through start-up or acquisition: A learning perspective, Academy of Management Journal 41(1): 7-26.

Bartlett CA, Ghoshal S. 1989. Managing across borders: The transnational solution, Boston, MA: Harvard Business School Press.

Benito GRG, Lunnan R, Tomassen S. 2011. Distant encounters of the third kind: multinational companies locating divisional headquarters abroad, Journal of Management Studies 28(2): 373-394.

Birkinshaw JM, Braunerhelm P, Holm U, Terjesen SA. 2006. Why do some multinational corporations relocate their headquarters overseas? Strategic Management Journal 27(7): 681-700.

Birkinshaw JM, Hood N. 1998. Multinational subsidiary evolution: Capability and charter change in foreign-owned subsidiary companies. Academy of Management Review 23(4): 773-795.

Birkinshaw JM, Morrison AJ. 1995. Configurations of strategy and structure in subsidiaries of multinational corporations, Journal of International Business Studies 26(4): 729-753.

Blalock G, Simon DH. 2009. Do all firms benefit equally from downstream FDI? Journal of International Business Studies 40(7): 1095-1112.

Buckley PJ. 2009. The impact of the global factory on economic development, Journal of World Business, 44(2): 131-143.

Cantwell J, Mudambi R. 2005. MNE competence-creating subsidiary mandates, Strategic Management Journal 26(12): 1109-1128. 
Chang SJ, van Witteloostuijn A, Eden L. 2010. From the editors: Common method variance in international business research, Journal of International Business Studies 41(2): 178-184.

Chen MJ. 1996. Competitor analysis and interfirm rivalry: Toward a theoretical integration, Academy of Management Review 21(1): 100-134.

Ciabuschi F, Dellestrand H, Martin OM. 2011. Internal embeddedness, headquarters involvement, and innovation importance in multinational enterprises, Journal of Management Studies, 48: 1612-1639.

Colakoglu S, Caligiuri P. 2008. Cultural distance, expatriate staffing and subsidiary performance: The case of US subsidiaries of multinational corporations, International Journal of Human Resource Management 19(2): 223-239.

Dawar N, Chattopadhyay A. 2002. Rethinking marketing programs for emerging markets, Long Range Planning 35(5): 457-474.

De la Torre JR. 1971. Exports of manufacturing goods from developing countries: Marketing factors and the role of foreign enterprise, Journal of International Business Studies 2(1): 26-39.

Devinney TM, Midgley DF, Venaik S. 2000. The optimal performance of the global firm: Formalizing and extending the integration-responsiveness framework, Organization Science 11(6): 674-695.

Doh J, Bunyaratavej K, Hahn ED. 2009. Separable but not equal: The location determinants of discrete services offshoring activities, Journal of International Business Studies 40(6): 926-943.

Dow D. 2006. Adaptation and performance in foreign markets: evidence of systematic under-adaptation, Journal of International Business Studies 37(2): 212-226.

Doz Y, Bartlett C, Prahalad CK. 1981. Global competitive pressures and host country demands: Managing tensions in MNCs. California Management Review 23(3): 6374.

Dunning JH. 1998. Location and the multinational enterprise: A neglected factor? Journal of International Business Studies 29(1): 45-66.

Dunning JH, Lundan S. 2008. Multinational enterprises and the global economy, $2^{\text {nd }}$ ed., Cheltenham: Elgar. 
Dunning JH, Narula R. 2000. Industrial development, globalisation and multinational enterprises: New realities for developing countries, Oxford Development Studies, 28(2): 141- 167.

Egelhoff WG. 1982. Strategy and structure in multinational corporations: An information-processing approach, Administrative Science Quarterly 27(3): 435-458.

Estrin S, Meyer KE, Wright M, Foliano F. 2008. Export propensity and intensity of subsidiaries in emerging economies, International Business Review 17(5): 574-586.

Estrin S, Baghdasaryan D, Meyer KE. 2009. Institutional distance and human resource distance in international business strategies in emerging economies, Journal of Management Studies 46(7): 1171-1196.

Garcia-Pont C, Canales JI, Noboa, F. 2009. Subsidiary strategy: The embeddedness component, Journal of Management Studies 46(2): 182-214.

Ghemawat P. 2007. Redefining global strategy, Boston: Harvard Business School Press.

Govindarajan V, Ramamurti R. 2011. Reverse innovation, emerging markets, and global strategy, Global Strategy Journal 1(2): 191-205.

Greene WH. 2002. Econometric analysis (5th ed.), London: Prentice Hall.

Grewal R, Chandrashekaran M, Dwyer FR. 2008. Navigating local environments with global strategies: A contingency model of multinational subsidiary performance, Marketing Science 27(5): 886-902.

Gupta AK, Govindarajan V. 2000. Knowledge flows within multinational corporations, Strategic Management Journal 21: 473-496.

Harzing AWK. 2002. Acquisition v greenfield investments: International strategy and management of entry modes, Strategic Management Journal 23(3): 211-227.

Hennart JF. 2009. Down with MNE-centric theories! Market entry and expansion as the bundling of MNE and local assets, Journal of International Business Studies 40: 1432-1454.

Hennart, JF. 2012. Emeging market multinationals and the theory of the multinational enterprise, Global Strategy Journal 2(3): 168-187.

Hofstede G. 1980. Culture's Consequences: International Differences in Work-Related Values. Beverly Hills CA: Sage Publications. 
Hofstede G. 2010. The GLOBE debate: Back to relevance, Journal of International Business Studies 41: 1339-1346.

House RJ, Hanges, PJ, Javidan M, Dorfman PW, Gupta V. eds. 2004. Culture, leadership, and organisations: The GLOBE study of 62 societies. Thousand Oaks, CA: Sage Publications.

Javidan M, Dorfman PW, de Luque MS, House RJ. 2006. In the eye of the beholder: cross cultural lessons in leadership from project GLOBE, Academy of Management Perspectives 20(1): 67-90.

Jensen R, Szulanski G. 2004. Stickiness and adaptation of organizational practices in cross-border knowledge transfers, Journal of International Business Studies 35(6): 508-524.

Kedia BM, Mukherjee D. 2009. Understanding offshoring: A research framework based on disintegration, location and externalization advantages, Journal of World Business 44(3): 250-261.

Kobrin S. 1991. An empirical analysis of the determinants of global integration, Strategic Management Journal 12(S1): 17-31.

Kogut B. 1985. Designing global strategies: Comparative and competitive value-added chains, Sloan Management Review 26(1): 15-28.

Kogut B, Singh H. 1988. The effect of national cultural distance on the choice of entry mode, Journal of International Business Studies 19(3): 411-432.

Kostova T. 1999. Transnational transfer of strategic organizational practices: A contextual perspective, Academy of Management Review 24: 308-324.

Kostova T, Roth K. 2002. Adoption of an organizational practice by subsidiaries of multinational corporations: Institutional and relational effects, Academy of Management Journal, 45(2): 215-233.

Kostova T, Roth K, Dacin T. 2008. Institutional theory in the study of multinational corporations: A critique and new directions, Academy of Management Review, 33(4): 994-1106.

Koza MP, Tallman S, Ataay A. 2011. The strategic assembly of global firms: A microstructural analysis of local learning and global adaptation, Global Strategy Journal 1(1): 27-46. 
Larimo J. 2003. Form of investment by Nordic firms in world markets, Journal of Business Research 56(10): 791-803.

Li J, Li Y, Shapiro D. 2012. Knowledge seeking and outward FDI of emerging market firms: The moderating effect of inward FDI, Global Strategy Journal 2(4): 277295.

Liu W. 2007. KFC in China: Secret Recipe for Success, New York: Wiley.

Manning S, Massini S, Lewin A. 2008. A dynamic perspective on next generation offshoring: The global sourcing of science and engineering skills, Academy of Management Perspectives 22(3): 35-54.

Meyer KE. 2006. Globalfocusing: From domestic conglomerate to global specialist, Journal of Management Studies 43(5): 1109-1144.

Meyer KE, Estrin S, Bhaumik SK, Peng MW. 2009a. Institutions, resources, and entry strategies in emerging economies, Strategic Management Journal 30(1): 61-80.

Meyer KE, Mudambi R, Narula R. 2011. Multinationals and local contexts, Journal of Management Studies 48(2): 235-253.

Meyer KE, Peng MW. 2005. Probing theoretically into Central and Eastern Europe:

Transactions, resources and institutions, Journal of International Business Studies 36 (6): 600-621.

Meyer KE, Sinani E. 2009. When and where does foreign direct investment generate positive spillovers, Journal of International Business Studies 40(7): 1075-1094.

Meyer KE, Wright M, Pruthi, S. 2009b. Managing knowledge in foreign entry strategies: a resource-based analysis. Strategic Management Journal 30(5): 557-574.

Mudambi R. 2008. Location, control and innovation in knowledge-intensive firms, Journal of Economic Geography 8(5): 699-725.

Peng MW. 2011. The global strategy of emerging multinationals from China, Global Strategy Journal 2(2): 97-107.

Prahalad CK, Doz Y. 1987. The multinational mission: Balancing local demands and global vision, New York: Free Press.

Quelch J, Jocz KE. 2012. All business is local: Why place matters more than ever in a global, virtual world, London: Portfolio.

Ricardo D. 1817. The Principles of Political Economy and Taxation. New York: Dutton. 
Roth K, Morrison AJ. 1990. An empirical analysis of the integration-responsiveness framework in global industries, Journal of International Business Studies 21(3): 541-561.

Rugman AM. 1982. New Theories of the Multinational Enterprise. New York: Taylor and Francis.

Rugman AM, Verbeke A. 2001. Subsidiary-specific advantages in multinational enterprises, Strategic Management Journal 22(3): 237-250.

Rugman AM, Verbeke A. 2004. A perspective on regional and global strategies of multinational enterprises, Journal of International Business Studies 35: 3-18.

Rugman AM, Verbeke A, Yuan W. 2011. Re-conceptualizing Bartlett and Ghoshal's classification of national subsidiary roles in the multinational enterprise, Journal of Management Studies 48(2): 253-277.

Santangelo G, Meyer KE. 2011. Extending the internationalization process model: Increases and decreases of MNE commitment in emerging economies, Journal of International Business Studies 42(7): 894-909.

Shenkar O. 2001. Cultural distance revised: toward a more rigorous conceptualization and measurement of cultural differences. Journal of International Business Studies 32(4): 519-535.

Singh J. 2008. Distributed R\&D, cross-regional knowledge integration and quality of innovative output, Research Policy 37(1): 77-96.

Slangen AHL, Hennart JF. 2008. Do foreign greenfields outperform foreign acquisitions or vice versa? An institutional perspective, Journal of International Business Studies 45(7): 1301-1328.

Smith KG, Ferrier WJ, Ndofor H. 2001. Competitive dynamics research: critique and future directions. In: Handbook of Strategic Management, Hitt M, Freeman RE, Harrison J (eds). Blackwell Publishers: London.

Solberg CA. 2000. Standardization or adaptation of the international marketing mix: The role of the local subsidiary representative, Journal of International Marketing 8(1): 78-98.

Taggart JH. 1997. Autonomy and procedural justice: A framework for evaluating subsidiary strategy, Journal of International Business Studies 28(1): 51-76. 
Tallman S, Chacar A. 2011. Knowledge accumulation and dissemination in MNEs: A practice-based framework, Journal of Management Studies 28(2): 278-304.

Tihanyi L, Griffith D A, Russell CL. 2005. The effect cultural distance on entry mode choice, international diversification, and MNE performance: A meta-analysis, Journal of International Business Studies, 36(3):270-283.

Verbeke A, Yuan W. 2013. The drivers of multinational enterprise subsidiary entrepreneurship in China: A New Resource-Based View Perspective, Journal of Management Studies 50(2): 236-258.

Xu D, Meyer, KE. 2013. Linking theory and context: Strategy research in emerging economies, Journal of Management Studies, DOI: 10.1111/j.14676486.2012.01051.x.

Yang QA, Mudambi R, Meyer KE. 2008. Conventional and reverse knowledge flows in multinational corporations, Journal of Management, 34(5): 882-902.

Yu TY, Cannella AA. 2007. Rivalry between multinational enterprises: An event history approach, Academy of Management Journal 50(3): 665-686.

Zaheer A, Hernandez E. 2011. The geographic scope of the MNE and its alliance portfolio: Resolving the paradox of distance, Global Strategy Journal 1(1): 109126.

Zaheer S, Nachum L. 2011. Sense of place: From location resources to MNE locational capital, Global Strategy Journal 1(2): 96-108.

Zaheer S, Schomaker SM, Nachum L. 2012. Distance without direction: restoring credibility to a much-loved construct, Journal of International Business Studies 43(1): 18-27. 
Figure 1: IRE Framework of Subsidiary Strategy

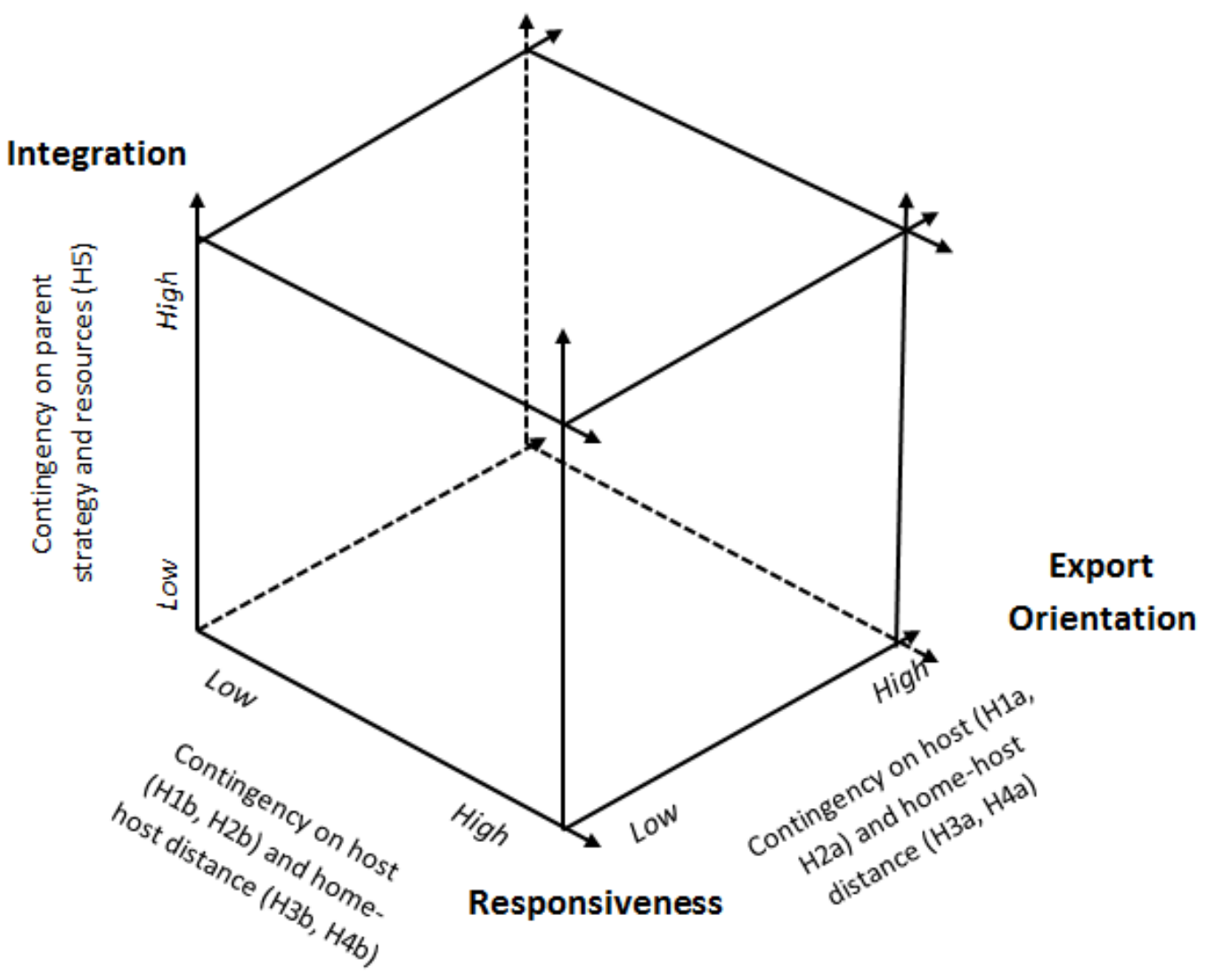

Table 1: Summary of Predicted Effects

\begin{tabular}{lcccc}
\hline & & integration & responsiveness & export orientation \\
\hline Local human resources & H1 & n.p. & + & - \\
Local competitor resources & H2 & n.p. & + & + \\
Cultural distance & H3 & n.p. & - & + \\
Human resource distance & H4 & n.p. & - & + \\
Parent MNE competences & H5 & + & n.p. & n.p. \\
\hline
\end{tabular}

n.p. $=$ no prediction 
Table 2: Correlations and descriptive statistics.

\begin{tabular}{|c|c|c|c|c|c|c|c|c|c|c|c|c|c|c|c|}
\hline & & mean & SD & 1 & 2 & 3 & 4 & 5 & 6 & 7 & 8 & 9 & 10 & 11 & 12 \\
\hline 1 & Responsiveness & .049 & 1.02 & 1 & & & & & & & & & & & \\
\hline 2 & Integration & .106 & .968 & -.30 & 1 & & & & & & & & & & \\
\hline 3 & Export-orientation & .011 & .975 & -.28 & .12 & 1 & & & & & & & & & \\
\hline 4 & Local human resources & 3.98 & .321 & -.02 & .02 & -.22 & 1 & & & & & & & & \\
\hline 5 & Local competitor resources & 2.98 & .482 & .26 & -.07 & .04 & -.33 & 1 & & & & & & & \\
\hline 6 & Distance culture & 5.34 & 1.10 & .08 & -.02 & .03 & -.23 & .23 & 1 & & & & & & \\
\hline 7 & Distance human resources & 2.58 & 1.09 & -.23 & .10 & .13 & .19 & -.26 & -.04 & 1 & & & & & \\
\hline 8 & Subsidiary age & 8.09 & 2.82 & .00 & .02 & -.10 & .05 & -.12 & .05 & -.04 & 1 & & & & \\
\hline 9 & Diversified - related & .307 & .452 & .08 & .02 & -.04 & -.05 & .06 & .04 & .03 & .01 & 1 & & & \\
\hline 10 & Diversified - unrelated & .065 & .248 & -.09 & .03 & .00 & -.05 & -.04 & .01 & .16 & .07 & -.18 & 1 & & \\
\hline 11 & Relative size & 3.26 & 1.63 & .04 & -.07 & .16 & -.08 & .01 & .07 & -.18 & .09 & -.12 & -.12 & 1 & \\
\hline 12 & R\&D Intensive & 2.57 & 2.11 & -.07 & .21 & -.01 & .05 & -.03 & -.04 & .12 & .01 & -.09 & .07 & .15 & 1 \\
\hline 13 & CEE operations & .497 & .501 & -.03 & .05 & -.15 & .05 & -.02 & .05 & .05 & -.08 & .05 & .00 & -.18 & -.00 \\
\hline
\end{tabular}


Table 3: Estimation of Strategy Choice

\begin{tabular}{|c|c|c|c|c|}
\hline & & Integration & Responsiveness & $\begin{array}{c}\text { Export- } \\
\text { orientation }\end{array}$ \\
\hline \multicolumn{5}{|l|}{ Explanatory variables } \\
\hline Local human resources & $H 1 a / b$ & $.081(.189)$ & $.116(.184)$ & $-.236(.118) *$ \\
\hline Local competitors & $H 2 a / b$ & $.028(.135)$ & $.440(.130) * * *$ & $.395(.164) * *$ \\
\hline Distance of culture & $H 3 a / b$ & $.002(.052)$ & $.019(.050)$ & $-.007(.045)$ \\
\hline $\begin{array}{l}\text { Distance in human } \\
\text { resources }\end{array}$ & $H 4 a / b$ & $.005(.055)$ & $-.126(.053) *$ & $.169(.047) * * *$ \\
\hline \multicolumn{5}{|l|}{ Parent MNE Variables } \\
\hline R\&D Intensive & & $.106(.036) * * *$ & $-.004(.035)$ & $-.029(.028)$ \\
\hline CEE operations & & $.045(.110)$ & $-.060(.107)$ & $-.238(.095)^{* *}$ \\
\hline Diversified unrelated & & $-.033(.224)$ & $-.150(.219)$ & $.007(.197)$ \\
\hline Diversified related & & $.111(.120)$ & $.132(.117)$ & $.005(.105)$ \\
\hline \multicolumn{5}{|l|}{ Link variables } \\
\hline Responsiveness & & $-.256(.059) * * *$ & --- & $-.173(.052) * * *$ \\
\hline Integration & & --- & $-.244(.056) * * *$ & $.063(.052)$ \\
\hline Export-orientation & & $.082(.068)$ & $-.215(.065) * * *$ & --- \\
\hline \multicolumn{5}{|l|}{ Control variables } \\
\hline Age & & $-.003(.020)$ & $.006(.019)$ & $-.034(.017)^{*}$ \\
\hline Relative size & & $-.036(.036)$ & $.045(.035)$ & $.061(.031) \dagger$ \\
\hline R\&D control & & $.167(.174)$ & -.082 (.171) & $.207(.153)$ \\
\hline Industry dummies (eight) & & Yes $* * *$ & Yes $\dagger$ & Yes $* * *$ \\
\hline Constant & & $-.618(1.04)$ & $-1.90(1.01)$ & $1.045(.095)$ \\
\hline F-statistic $(20,285)$ & & $2.75^{* * *}$ & $5.58 * * *$ & $8.32 * * *$ \\
\hline Adj-R ${ }^{2}(\%)$ & & $10.3 \%$ & $23.1 \%$ & $32.4 \%$ \\
\hline Observations & & 306 & 306 & 306 \\
\hline
\end{tabular}

Notes:

Standard errors in parentheses; levels of significance: $\dagger=10 \%, *=5 \%$, $* *=1 \%, * * *=0.5 \%$. 